\title{
THE INFLUENCE OF MUSCLE SORENESS ON THE SPEED OF PERFORMING A MOTOR REACTION SPEED TASK IN FOOTBALL GOALKEEPERS DURING A TRAININGG CAMP
}

\author{
Jarosław Muracki \\ University of Szczecin, Faculty of Health and Physical Education, Institute of Physical Culture Sciences \\ Address for correspondence: \\ Jarosław Muracki \\ Al. Piastów 40b, blok 6, 71-065 Szczecin, Poland \\ E-mail: jaroslaw.muracki@usz.edu.pl
}

Ahstract Aim: To investigate the influence of muscle soreness on the speed of performing a motor reaction speed task in football goalkeepers.

Methods: Twenty-four young healthy football goalkeepers, aged 16-18 years old (average $16.7 \pm 0.67$ year), with an average body height of $175.6 \pm 5.4 \mathrm{~cm}$ and body weight of $65 \pm 5 \mathrm{~kg}$, participated in a study conducted during a 6 -day training camp. The first day, referred to as day 0 , was intended for initial tests and the following 5 days, referred to as days $1-5$, consisted of training. On day 0 , before the training period, anthropometric parameters such as weight and height were measured, subjects were questioned to determine the rate of perceived exertion (RPE) and perceived psychophysical readiness (PPR), a speed test with motor reaction choice (ST) was performed using a Smart Speed System and areas with muscle soreness (MS) were recorded by means of a computer tablet with the Navigate Pain application. The goalkeepers participated in two training sessions on each of the following 5 days. Before each training session, the same speed test was performed. Lap times for $5 \mathrm{~m}$ and $15 \mathrm{~m}$ were recorded. After the second training session each day, the participants drew digital pain maps using a computer tablet, marking separate areas of the body where they felt muscle soreness. These data were consolidated and the total area was analyzed to investigate if, throughout the training, there were any changes to the size of the area that was indicated as having MS. A categorization of body areas was also made to determine areas where muscle soreness was most frequently indicated. Each training session was monitored with heart rate (HR) registration and each goalkeeper determined his fatigue (RPE) and readiness to exercise (PPR) on a 1-10-point scale.

Results: Twenty-three out of twenty-four (98.5\%) goalkeepers indicated that they had MS during the study. Day 2 showed the highest incidence rate with 21 participants indicating that they felt MS. The biggest area of MS was also indicated on day 2, yet statistical analysis did not show significant differences in the area of MS between the training days. MS was most often indicated in the upper leg, i.e. the thighs. The average time of the first $5 \mathrm{~m}$ was $1.3[\mathrm{~s}](\mathrm{SD}=0.09)$, ranging from $1.28[\mathrm{~s}]$ to 1.33 [s], while the average time of the following $10 \mathrm{~m}$ was 2.07 [s] (SD $=0.18$ ), ranging from 2.04 to 2.1 [s]. The average total speed test time equaled 3.37 [s] $(S D=0.21)$, ranging from 3.33 to 3.38 . Statistical analysis did not show significant differences in any of the results between the training days.

Conclusions: Most of the goalkeepers felt muscle soreness as an effect of specific goalkeeper training, measured by indicating painful zones on digital pain drawings. In this study, where muscle soreness was induced by technical-tactical specific goalkeeper training, no significant changes were noticed in the speed of performing a motor speed test with reaction choice or on the area of muscle soreness indicated on digital pain drawings, although almost every goalkeeper had a large area of muscle soreness. 
Discussion: Many studies show that delayed onset muscle soreness (DOMS) causes a decrease in strength, power, range of motion and speed. However, in many cases, these studies are designed to induce high intensity DOMS and then conduct isolated motor skill tests. In this study the objective was not to induce high intensity DOMS but to investigate the effect of muscle pain, which is present naturally during training processes, and then assess its effect on a speed test which reflects real game situations - with a component of reaction choice and change of movement and direction. Approaching the subject from a different viewpoint allows us to see that the reliable assessment of the psychophysical state of players, made by observing their actions on the pitch or even using photocells to measure motion speed, is difficult without an insight into the parameters of soreness that players experience. These can be monitored, for example, through digital pain mapping software.

Key Words goalkeeper, DOMS, muscle soreness, pain, speed, reaction

\section{Introduction}

The technical report and statistics of the 2014 FIFA World Cup in Brazil_underlined the importance of goalkeepers and coaches' education in the training process in senior and youth football (Sieboth et al., 2014). A goalkeeper's actions during match play include several interventions such as diving, jumping, tackling, 1v1 duels, intercepting crosses, throwing and passing with the feet. Most of the actions are explosive movements; changes of direction, accelerating, decelerating, landing, jumping or sprints which last up to a few seconds. Many authors emphasize the role of speed as crucial for the effectiveness of a goalkeepers' actions (Bergier, 2004; Di Salvo, Benito, Calderón, Di Salvo, Pigozzi, 2008; Knoop, Fernandez-Fernandez, Ferrauti, 2013; Ziv, Lidor, 2011; Deprez et al., 2015; Padulo, Haddad, Ardigò, Chamari, Pizzolato, 2015). Goalkeeper fitness and ability tests often use speed tests (Knoop et al., 2013; Rebelo et al., 2013; Rebelo-Gonçalves, Figueiredo, Coelho-E-Silva, Tessitore, 2016). Goalkeeper technical-tactical training tends to simulate real game situations, but with a higher number of repetitions (Pawłowski, Trzaskoma, 2012; Goliński, Muracki, Wolański, Klich, Murawska-Ciałowicz, 2016). A large number of repetitions aims to improve technique and tactics but may cause overtraining which results in increased soreness, pain, excessive or constant fatigue, loss of optimal physical condition and an increase in the risk of injury (Carfagno, Hendrix, 2014).

Football is a team sport with a high risk of injury (DeHaven, Lintner, 1986; Hootman, Dick, Agel, 2007). K. Kristenson, M. Waldén, J. Ekstrand and M. Hägglund (2013), who recorded 6,140 injuries in 1,401 players from 26 clubs during 797,389 hours of exposure across 9 consecutive seasons, claim that approximately 1 injury occurs for every 130 hours of athletic exposure (0.77 injury incidence per $100 \mathrm{~h}$ ) (Kristenson et al., 2013). Another cohort study by M. Hägglund, M. Waldén, R. Bahr and J. Ekstrand (2005) demonstrated a 0.78 injury incidence per 100 hours of exposure. Many football injuries involve muscles, depending on the level that is being played at. In professional players, 20-46\% of all injuries are muscle injuries (Hägglund, Waldén, Ekstrand, 2003) and in amateurs - 18-23\% (Chamari, Haddad, Wong, Dellal, Chaouachi, 2012).

Goalkeepers have a lower injury risk when compared with field players but are more likely to suffer from upper limb injuries (Aoki, O’Hata, Kohno, Morikawa, Seki, 2012; Della Villa, Mandelbaum, Lemak, 2018). A study analyzing elite Norwegian goalkeepers showed injury incidence equal to 27.9 per 1,000 match hours, 23.6 for specific goalkeeper training and 9.1 for other types of training. Injuries of the upper limbs represented $36 \%$ of all injuries (Strand, Krosshaug, Andersen, 2011). In a study using questionnaires, over $72 \%$ of young male football goalkeepers reported an injury within the last 12 months, over $88 \%$ of which occurred during training. The most common were acute injuries (nearly $77 \%$ ), with fractures/subluxations of fingers, and thigh muscle strains/tears 
reported most often. The other $23 \%$ were injuries from overuse which most frequently involved the knee and pelvic girdle (Błażkiewicz, Grygorowicz, Białostocki, Czaprowski, 2018).

There are numerous definitions of injury which accent chosen aspects of this phenomenon. The World Health Organization (WHO) developed the International Classification of External Causes of Injury (ICECI) which classifies injuries by: mechanisms, objects/substances which cause injury, a place of occurrence, an activity when injured, and a role of human intent. In sport, an injury is most commonly defined as damage to the body which causes a break in training or in performing an activity (time-loss injury). This definition does not include a situation in which there is damage to the body or pain, but the athlete is not excluded from training or playing. According to this definition, the same pain or damage to the body can be a time-loss injury for one athlete but does not need to be an injury at all for another. In the Consensus statement on injury definitions and data collection procedures in studies of football (soccer) injuries' an injury was described as "any physical complaint sustained by a player that results from a football match or football training, irrespective of the need for medical attention or time loss from football activities". This means that everything a person complains about is classified as injury. The "Consensus" outlined another two types of injuries - a medical attention injury (injuries which need medical attention) and a time-loss injury (injuries which eliminate an athlete from full participation in training or playing) (Fuller et al., 2006). "Physical complaint" injuries result in the highest injury rate, the "Medical attention" definition encompasses a smaller number of injuries, and the "time loss" definition has the lowest. In the "Consensus" statement, a traumatic injury is defined as an injury resulting from a specific, identifiable event, and an overuse injury is caused by repeated micro trauma without a single, identifiable event responsible for the injury (Fuller et al., 2006; Bahr, 2009).

Another aspect is pain and soreness. Soreness and pain are not only connected with acute injuries but also with overuse injuries in which they manifest as: pain in the affected area during an activity (which restricts performance), pain in the affected area during an activity (which does not restrict performance), pain in the affected area after an activity and chronic pain in the affected area, even after resting. R. Bahr (2009) claims that incidence can be very low using the time-loss or medical attention definitions despite the presence of a high prevalence of pain in pain indicating surveys. The DOMS mechanism is induced by muscle work, especially by exercises with an eccentric component such as being highly intensive or using explosive movements (Maclntyre, Reid, McKenzie, 1995; Hughes, Denton, Lloyd, Oliver, De Ste Croix, 2018; Tzatzakis et al., 2019), prolonged isometric work (Nie, Kawczynski, Madeleine, Arendt-Nielsen, 2005) or prolonged exertion (Paquette, Peel, Schilling, Melcher, Bloomer, 2017). A training load including explosive or high intensity movements causes a decrease in strength, speed and jumping performance as well as an increase of DOMS and creatine kinase (Tzatzakis et al., 2019). Prolonged exertion can also cause DOMS which affects the biomechanics of movement (Paquette et al., 2017). As well as this, muscle structure with DOMS can be damaged during goalkeeping in other ways leading to excessive stretching and tears. Prolonged musculoskeletal pain decreases motor activity (Lund, Donga, Widmer, Stohler, 1991) which can lower the effectiveness of the regeneration process.

Popular pain assessment tools include the Sports Inventory for Pain, the Wong-Baker FACES Rating Scale, the 0-10 Numeric Pain Rating Scale, the Visual Analogue Scale and the Verbal Pain Intensity Scale. These tools place little to no emphasis on the location of pain and how it changes. Digital pain drawings are a modern and reliable pain assessment method to record the location, area, intensity of pain and any changes in these parameters (Boudreau, Badsberg, Christensen, Egsgaard, 2016; Egsgaard, Christensen, Petersen, Brønnum, Boudreau, 2016; Muracki et al., 2019; Shaballout, Neubert, Boudreau, Beissner, 2019). 
In this study, the author's aim is to investigate whether football goalkeepers suffer pain as a result of training and investigate the impact of muscle soreness on the speed of their actions, characteristic for real game situations and based on goalkeepers' kinematics.

Aim: The aim of the study was to investigate the influence of muscle pain and soreness arising from training, on the speed of football goalkeepers in the specific conditions of their role.

\section{Methods}

\section{Papticipants}

Twenty-four young healthy male football goalkeepers aged 16-18 (average $16.7 \pm 0.67$ years) were involved in the study. The average body height was $175.6 \pm 5.4 \mathrm{~cm}$ and the average body mass, $65 \pm 5 \mathrm{~kg}$. The right upper limb and the right lower limb were indicated as dominant in every case. The participants had been training and playing as football goalkeepers for a minimum of 4 years and at the time of the study, were representing clubs from the highest regional leagues. All of the participants were deemed medically fit to play, had no contraindications to training and playing football and voluntarily agreed to participate in the study.

The exclusion criteria were as follows: present illness, present injury, previous severe injuries_or symptoms that affect feeling or movement, medical contraindications to playing football, illnesses that require the use of painkillers or any other medication.

\section{Study design}

The project was approved by the ethics committee. Subjects participated in the study of their own free will and were informed that they may terminate their participation at any time. In the case of minors, consent for their participation in the research was obtained from their parents or legal guardians. The study was conducted during a 6-day training camp. Before the start of the camp, the participants had from four to seven days of complete rest with no sport or recreational physical activity. Before the training period, on the first day, referred to as day "0", initial tests and checks were conducted. These included measuring anthropometric parameters such as weight and height, performing speed tests with reaction choice using the Smart Speed System and recording painful areas by means of a computer tablet with the Navigate Pain application (Figure 1).

\section{Speed test}

The speed test was designed to test starting and running speed combined with reaction and motion direction changes. It used the Smart Speed System consisting of gates with photocells equipped with programmable signal emitting lights. The device can also measure time. Four gates were set up in a $Y$ formation (Figure 2). The first gate started the timer and was $5 \mathrm{~m}$ away from the second gate. As the second gate was passed, the timer recorded the time of the lap and randomly selected an end gate where a photocell began blinking. After a voluntary start, the subject would sprint the $5 \mathrm{~m}$ from the first to the second gate and then the $10 \mathrm{~m}$ to the end gate where the light was blinking. Crossing one of the end gates ended the timer. Every participant completed the speed test 2 times before every training session and both records were included in the data analysis. Lap times were recorded for the first $5 \mathrm{~m}$ sprint, reaction time and following $10 \mathrm{~m}$ run and the total time $(15 \mathrm{~m})$. 

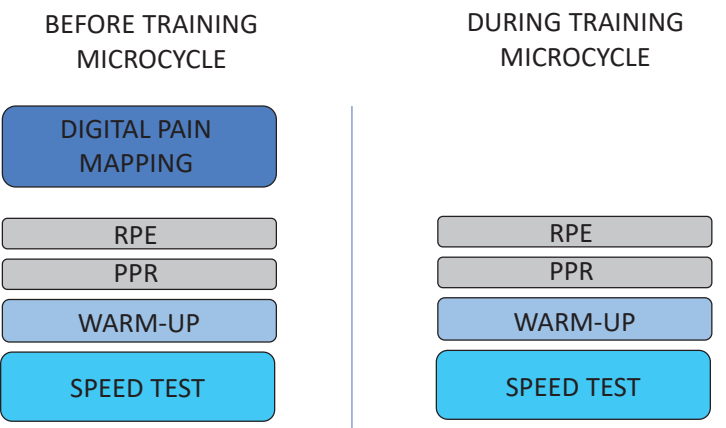

BEFORE EVERY

TRAINING

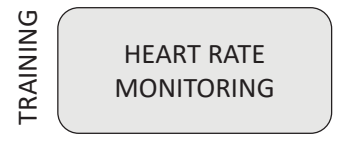

DURING EVERY

TRAINING

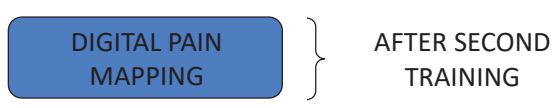

RPE - Rate of perceived exertion, PPR - Perceived Psychophysical Readiness.

Figure 1. Study design

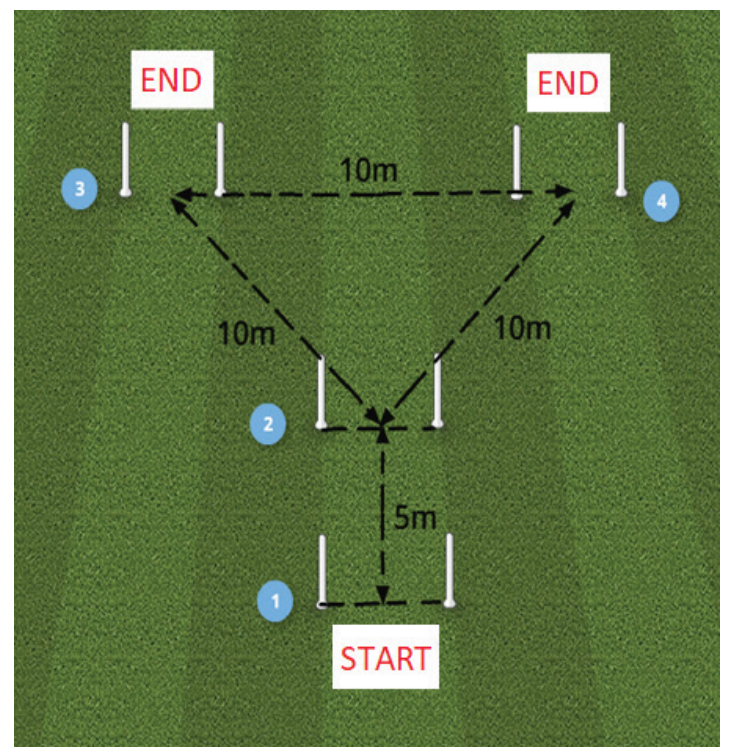

Instructions for the test taker:

1 - Stand in a starting position for running (one leg forward on the marked point) $30 \mathrm{~cm}$ in front of the first gate.

2 - Start at any time.

3 - Run as fast as you can to go through the first gate.

4 - One of the two end gates will blink - run as fast as you can to go through the blinking gate.

5 - Try to go as fast as you can, cross the gate and start decelerating a few meters after passing through the gate, do not stop at the gate line.

Figure 2. Speed test design 


\section{Goalkeeping exercise}

During training days $1-5$, there were 2 specialist tactical-technical goalkeeper training sessions each day. The first training session was at 11:00 am, and the second at 5:00 pm, both lasting for 1.5 hours. During the training sessions goalkeepers practiced exercises based on the game situations presented in Figure 3. The exercises involved shot stopping, intercepting crosses, throwing, defending in $1 \mathrm{v} 1$ duels and passing. There was no increased physical activity between the sessions and no physiotherapy was used during the camp. Before each training session the same speed test was performed.

\section{Long pass and 1v1 exercise}

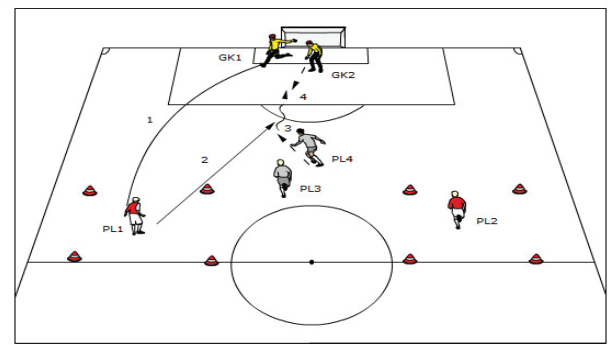

1 Goalkeeper 1 long pass to player 1 or 2

2 Player 1 (or 2 ) receives the ball and passes at the goal direction. 3 Player 4 (or 3 ) receives the ball and attacks the goal in $1 \mathrm{v} 1$ duel with goalkeeper 2 (or goalkeeper 1 ).
Shoot stopping exercise

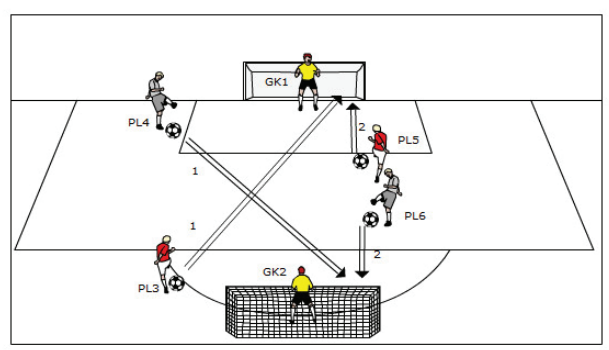

1 Players 3 and 4 shoot, goalkeepers 1 and 2 defend 2 Players 5 and 6 shoot the deflected ball or the second ball

\section{$1 \mathrm{v} 1$ and shoot stopping exercise}

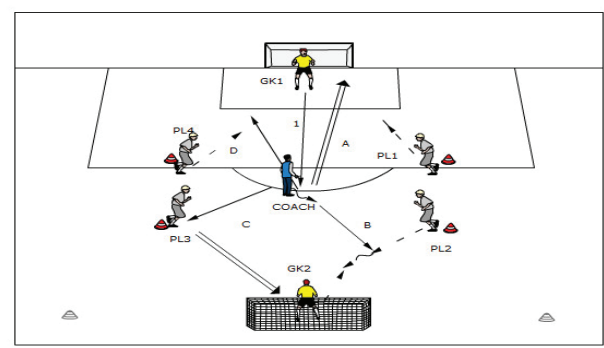

1 Goalkeeper 1 passes the ball to the coach Coach create one of the following situations:

A - Coach shoots, player runs to shoot the ball if goalkeeper deflects when defending the goal

$B$ - Coach passes the ball to the player and he goes into $1 \mathrm{v} 1$ due with goalkeeper who tries to defend the goal

$\mathrm{C}$ - Coach passes the ball to the player and he shoots and goalkeeper defends the goal

D - Coach passes the ball at the goal direction, the goalkeeper and the player compete to get the ball first

\section{Crosses interception exercise}

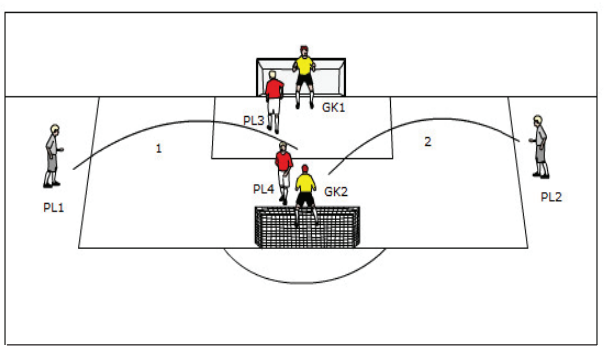

1 Player 1 crosses for goalkeeper 1 or 2

2 If the goalkeeper catches the ball, he throws it to the other side to player 2

Players 3 and 4 try to score or to prevent goalkeepers' intervention

Figure 3. Goalkeeping exercises 


\section{Digital pain mapping}

Each day after the second training session, the participants drew digital pain maps using a computer tablet (Lenovo Tab 10, TB-X103F). They were marking areas of the body where they felt muscle pain in the Navigate Pain application for Android. The participants were asked to use a finger to draw the area and location of the soreness on a 2D male body outline representing the anterior and posterior parts of the body. This method has a proven reliability and can be comparable with a traditional pen and paper method (Boudreau et al., 2016). The participants were asked to only indicate and draw muscle pain, i.e. pain localized within the muscle structure and not caused by a direct impact. A precise questioning algorithm was used to help the participants fully understand the request (Figure 5). Using the Navigate Pain application, the areas of MS were extracted and expressed as a total number of pixels. Each digital pain drawing was then reviewed in terms of the localization of the MS for further analysis. The posterior and anterior body schemes were divided into areas of large muscle groups according to anatomical and biomechanical factors and was based on our observations from previous studies (Figure 4). These data were then consolidated and analyzed to investigate how the size of the area of muscle soreness changed during the study and where muscle soreness was most frequently indicated.
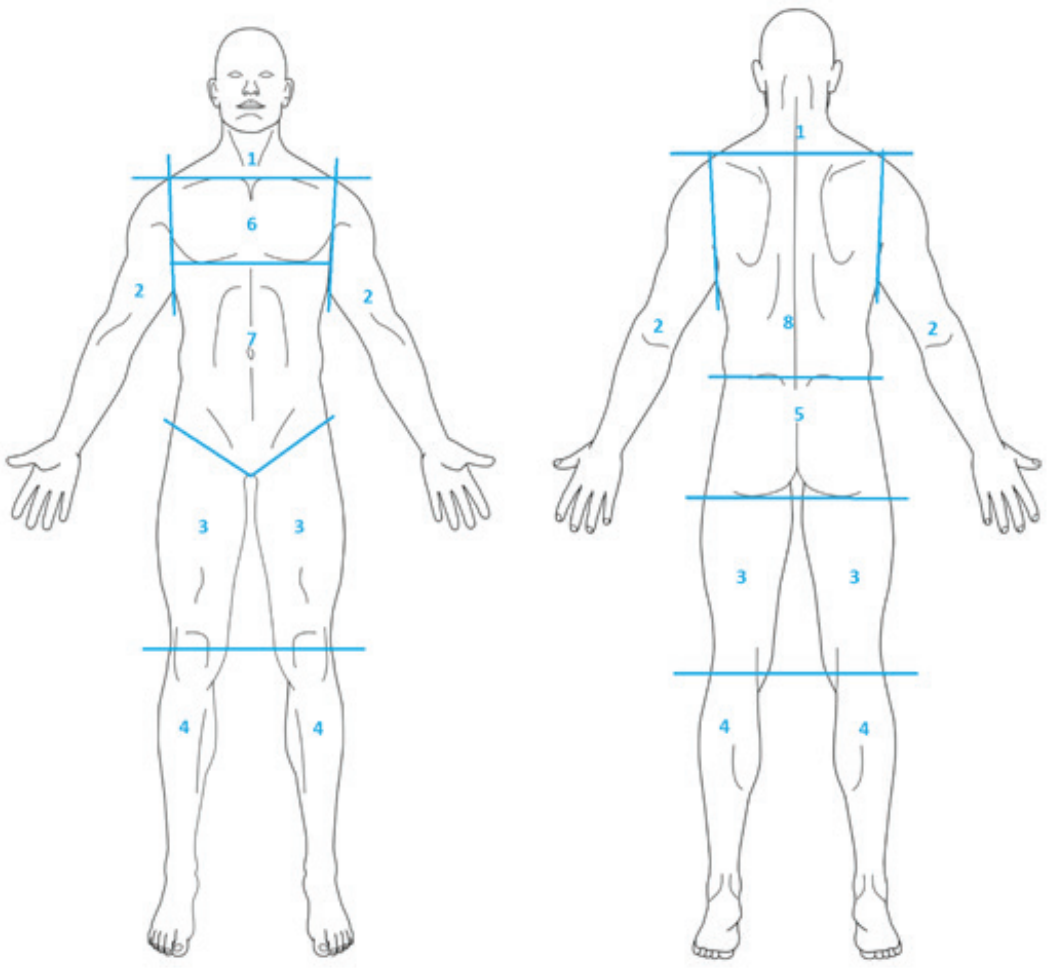

1 - shoulders and neck, 2 - upper limb, 3 - upper leg, 4 - lower leg, 5 - glutes, 6 - chest, 7 - abdomen, 8 - back.

Figure 4. Body areas 


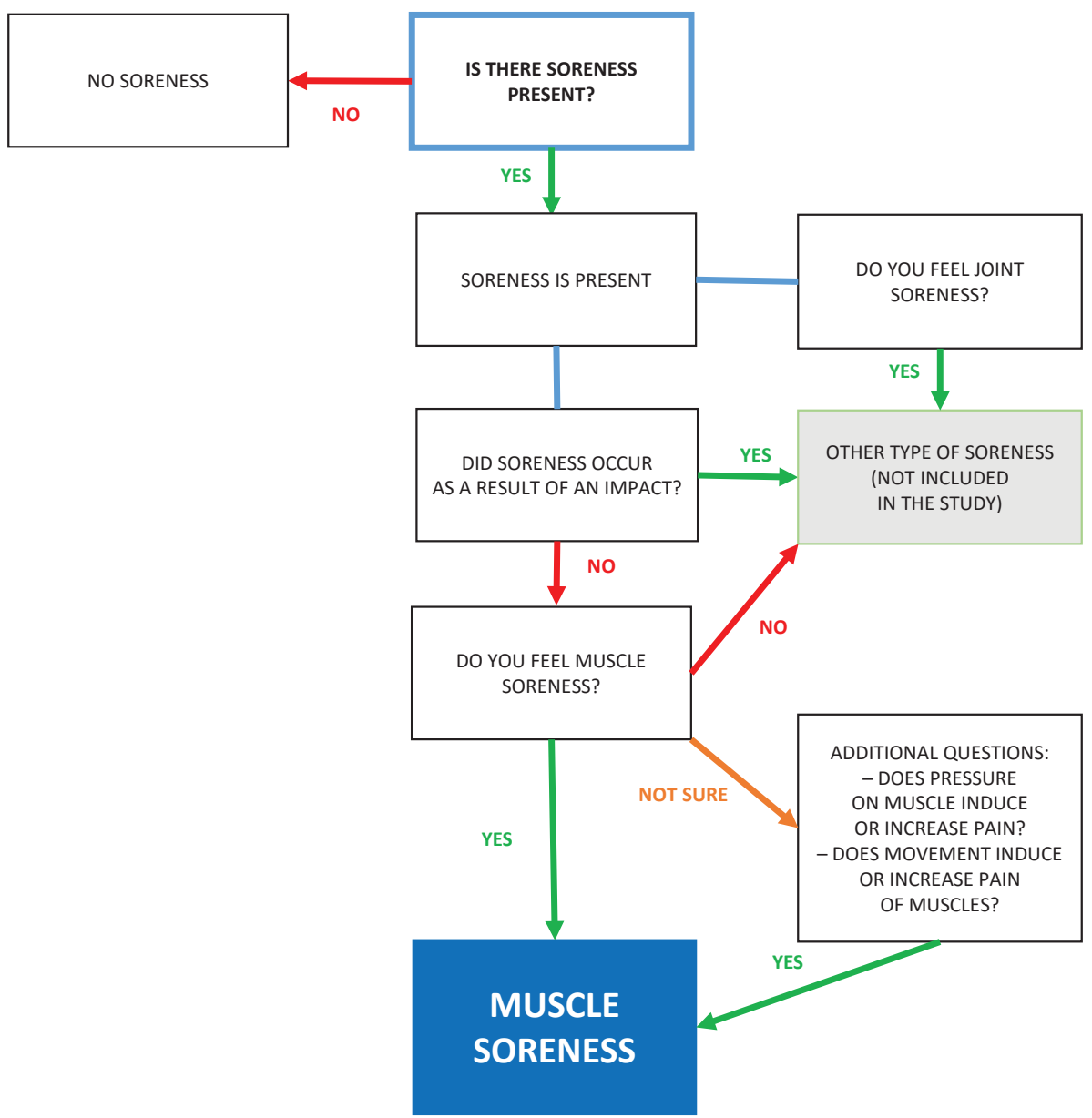

Figure 5. Questioning algorithm - type of soreness

\section{Training load monitoring results}

HR and self-reporting scales such as the Rate of Perceived Exertion are considered to be reliable and easy-to-use tools for assessing training load (Coutts, Rampinini, Marcora, Castagna, Impellizzeri, 2009). Each training session was monitored with HR registration (Polar Team System). Before starting training, the goalkeepers indicated their fatigue as a rate of perceived exertion (RPE) on a ten-point scale, where 1 was the lowest fatigue score and 10 was the highest. In a similar way, goalkeepers determined their perceived psychophysical readiness (PPR) to exercise on a ten-point scale, where 10 was the highest readiness to exercise and 1 was the lowest. The aims of monitoring these was to maintain the intensity of the training sessions, to observe the participants, avoid excessive fatigue and to control the goalkeepers' involvement in training. 


\section{Statistical analysis}

Statistical analysis was performed using the Statistical Package for Social Sciences (SPSS, IBM). To investigate the overall area of soreness reported by the goalkeepers, the total number of pixels for the areas was extracted. The Shapiro-Wilk test for normality was used to test the normality of the residuals. The pixel data of pain extent underwent the Friedman one-way repeated-measures analysis of variance (1-way RM ANOVA) to investigate the differences between the 5 days of training. Furthermore, to explore the change in the total area of muscle soreness from day 1 to 5 of the training camp, pixel data were subjected to the Wilcoxon signed-rank test.

The changes in speed test results were investigated by means of a one-way repeated measure analysis of variance (1-way RM ANOVA). The same test was used to investigate the differences of RPE and PPR between these days. The Bonferroni correction was applied where appropriate. The results are presented as mean \pm standard error, unless otherwise stated. Statistical significance for all analyses was accepted at $p<0.05$.

\section{Training load monitoring results}

The goalkeepers trained with maximal intensity for $4 \%$ of the total training time, at very high intensity - for $11 \%$, at high intensity - for $28 \%$, at moderate intensity - for $36 \%$ and at low intensity for $21 \%$ on average. The zones of intensity were calculated individually and were named maximal intensity for $90-100 \%$, very high $-80-89 \%$, high $-70-79 \%$, moderate $-60-69 \%$ and low $<60 \%$ HRmax. The maximal HR reached during the training sessions was $90.4 \pm 2.75 \%$. The average HR amounted to $66.1 \pm 2.1 \%$. There were no statistically significant changes between the training days $(p=0.05)$.

The rate of perceived exertion was 1,1 for day 0 , and for the following training days $1-5: 2.4 ; 2.4 ; 2.6,2.9$; 2.9 on average, respectively (Figure 6 ). The average RPE of all participants during training days $1-5$ was $2.6 \pm 0.8$. There were no statistically significant changes between results in the training days $(p=0.05)$.

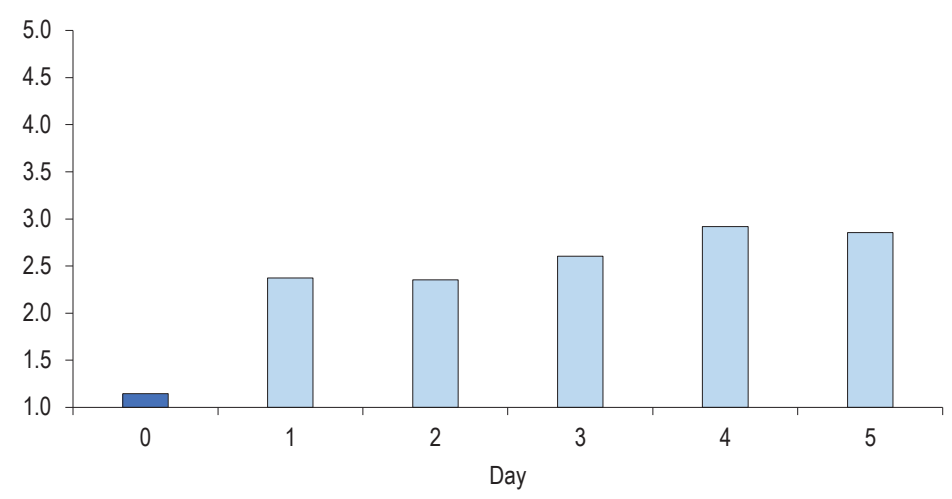

Scale $1-10$, where 1 is the lowest perceived exertion and 10 is the highest perceived exertion.

Figure 6. Average score of the Rate of Perceived Exertion across the study 
Perceived psychophysical readiness was 9.9 for day " 0 " and for the following training days $1-5: 8.9 ; 8.8 ; 8.5$; 8.1; 8.0 on average, respectively (Figure 7). The average PPR of all participants in training days $1-5$ was $8.5 \pm 1.13$. There were no statistically significant changes between results during the training days $(p=0.05)$.

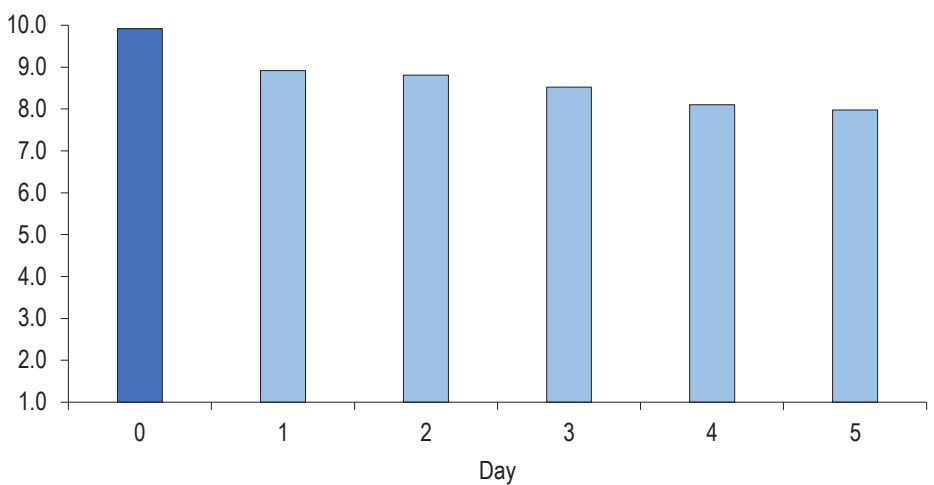

Scale $1-10$, where 1 is the lowest perceived psychophysical readiness and 10 is the highest perceived psychophysical readiness

Figure 7. Average score of Perceived Psychophysical Readiness across days

The analysis of training monitoring data leads to the conclusion that goalkeepers trained at a moderate to high intensity shown through the HR, claimed low RPE, as a measure of exertion, and a high PPR, as a measure of psychophysical readiness to upcoming training.

\section{Results}

During training days 1-5, twenty-three of twenty-four (95.8\%) goalkeepers indicated muscle soreness on digital pain mapping from the first to the last training day (Figure 8).

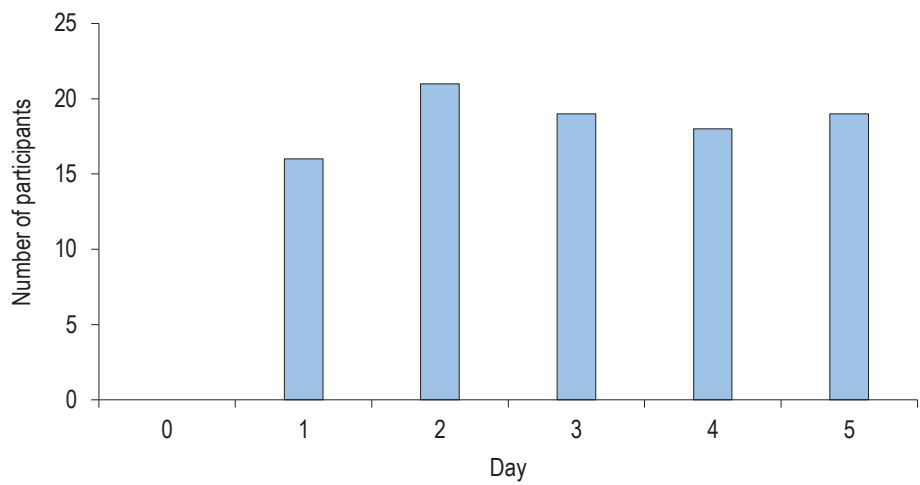

The maximal number of subjects indicating muscle soreness was 21 on the second training day.

Figure 8. Number of participants indicating muscle soreness across days 
Though the area of muscle soreness was biggest on day 2 (Figure 9), statistical analysis did not show significant differences between the training days $(p=0.05)$. Similarly, there were no statistically significant differences in size of the area of muscle soreness indicated on the front and back view of the body $(p=0.05)$.

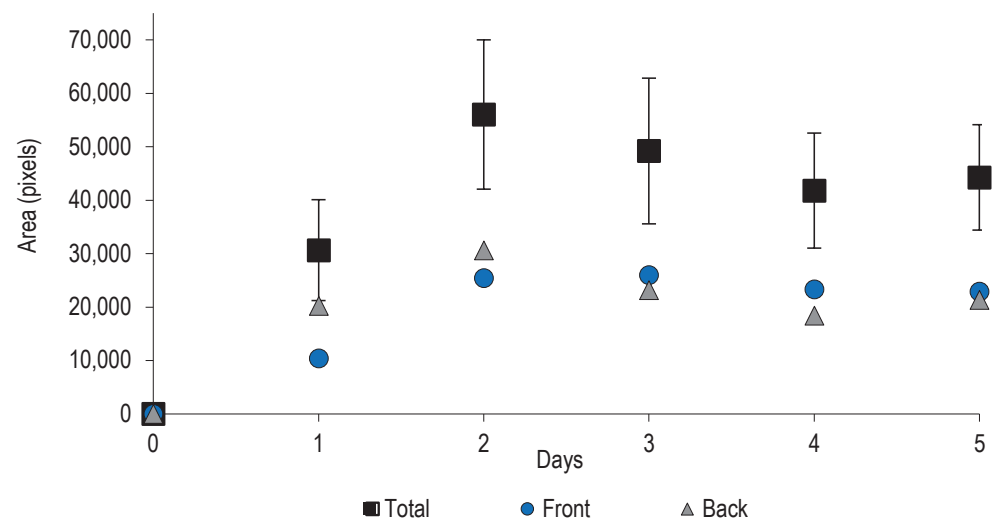

Figure 9. Muscle soreness area across days
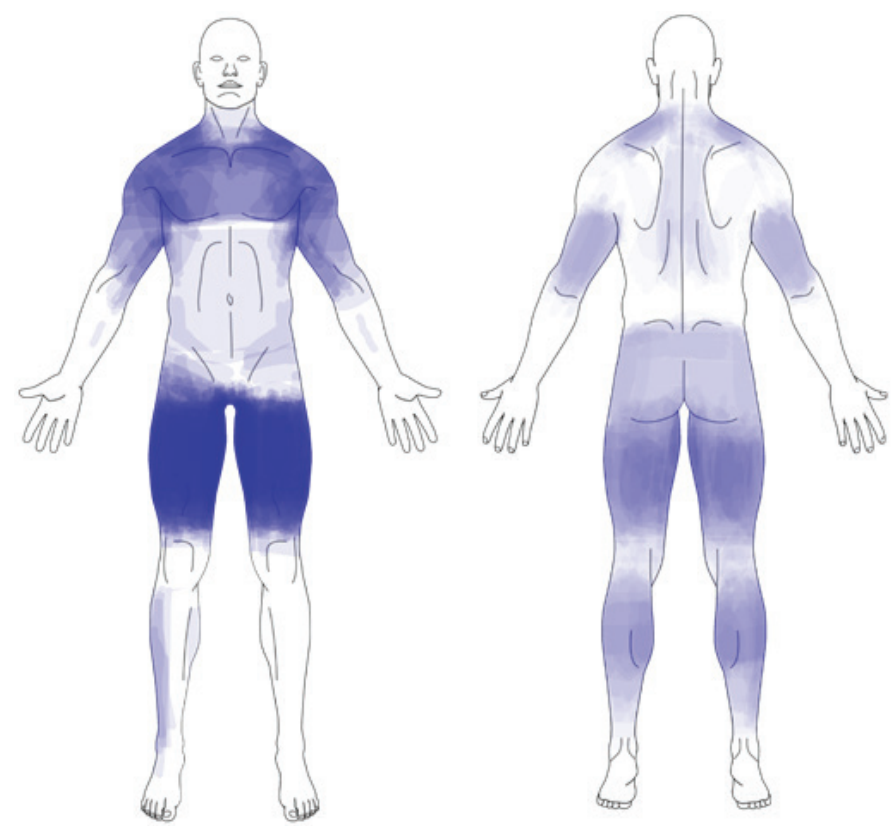

Front body area - left, back body area - right.

Figure 10. Muscle soreness - graphical representation of all 240 cards superimposed (120 - front view, 120 - back view) from the five training days of all 24 subjects 
Muscle soreness was most often localized in the area of the upper leg (Figure 10) - twenty-one out of twentyfour subjects indicated this area ( $88 \%$ ). The areas of muscle soreness which were the least frequently reported were the abdomen, back, gluteus muscles and shoulders and neck (Table 1).

Table 1. Localization of muscle soreness

\begin{tabular}{lcccccccc} 
& $\begin{array}{c}\text { Shoulders } \\
\text { and neck }\end{array}$ & Upper limb & Upper leg & Lower leg & Gluteus & Chest & Abdomen & Back \\
\hline Sum out of 24 & 7 & 8 & 21 & 9 & 7 & 8 & 5 & 5 \\
Percent of all & $29^{*}$ & 33 & $88^{*}$ & 38 & $29^{*}$ & 33 & $21^{*}$ & $21^{*}$ \\
\hline
\end{tabular}

${ }^{*}{ }^{2}(p=0.005)$.

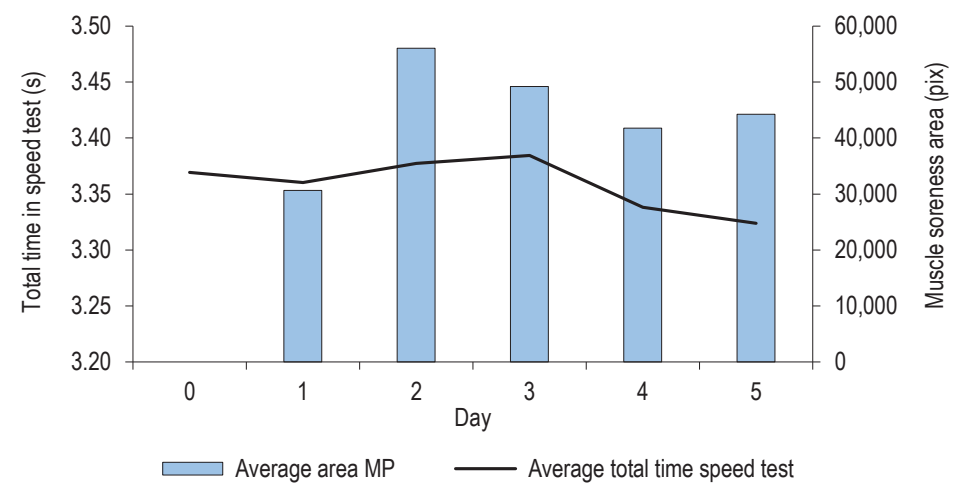

On day "zero" none of the subjects indicated muscle soreness and the speed test time was 3.37 (s)

Figure 11. Muscle soreness area and total time in speed test across training days

The results of the speed test in days $0-5$ were as follows: $3.37 ; 3.36 ; 3.38 ; 3.38 ; 3.34 ; 3.32$ (s) (Figure 11). There were no statistically significant changes between the days $(p=0.05)$. The results of the first $5 \mathrm{~m}$ (distance from the first to the second gate) in days $0-5$ were as follows: $1.27 ; 1.33 ; 1.31 ; 1.29 ; 1.31 ; 1.30$ (s). Statistical analysis did not show significant changes $(p=0.05)$. The results of the last $10 \mathrm{~m}$ (decision, change of direction and locomotion speed from the second to the third gate) in days $0-5$ were as follows: $2.04 ; 2.08 ; 2.07 ; 2.08 ; 2.06 ; 2.09$ (s). Again, there were no statistically significant changes between the days $(p=0.05)$.

\section{Discussion}

Many studies show that DOMS causes a decrease in strength, power, range of motion and speed, but in many cases these studies are designed to induce high intensity DOMS and use isolated motor skills tests (Tzatzakis et al., 2019; Nie et al., 2005; Kawczyński, Samani, Fernández-de-Las-Peñas, Chmura, Madeleine, 2012; Kawczyński et al., 2014). Other authors like Hughes emphasize the meaning of assessment the mechanism caused by real game or training situation (Hughes et al., 2018). In this study the objective was not to induce high intensity DOMS or muscle soreness but to investigate the effect of muscle pain which is naturally present during training processes, 
and assess its effect on speed tests that reflect real game situations - with a component of reaction choice and change of movement direction. In sport, fatigue monitoring aims to prevent excessive loads including excessive muscle soreness and the DOMS effect. It is already known that straight path running speed, especially for distances over $60 \mathrm{~m}$ with a voluntary start, has a poor correlation with the speed needed for acting in football match conditions. Due to these facts and a tendency of team management staff to choose the most effective and reliable goalkeeper for the first squad, author decided to investigate the muscle soreness effect arising in natural training conditions and its influence on the speed in a motor task based on real game situations.

Another approach argues that reliable assessment of the psychophysical state of players, made by observing their actions on the pitch or even using photocells to measure motion speed, is difficult without having an insight into the soreness and pain they feel. This can be monitored by, for example, digital pain mapping. In a long term perspective, at least four dimensions should be considered: training process, training and playing load, injury prevention and rehabilitation and playing performance. Training load is connected with a players' individual and team development. Injury prevention demands an optimization of training load which often leads to a decrease of intensity, training volume or even forces exclusion from training and playing process. Rehabilitation after an injury is nearly always connected with a time-loss period. Injury prevention and rehabilitation are strongly connected with physical preparation, for which training monitoring is crucial. Play performance is the result of many factors, only some of which can be directly influenced by training staff. The most significant besides the personal team squad are training process and injury prevention and rehabilitation. Taking these into consideration makes training monitoring even more important. Training monitoring can increase the quality of training process, injury prevention and rehabilitation. This is the main reason why the author considers monitoring pain as an important and easy way to get an insight into a players' condition as well as to analyze it in a long-term training and playing process.

\section{Conclusions}

1. Muscle soreness was indicated by the majority of goalkeepers.

2. The area of muscle soreness did not change significantly across training days.

3. Motor reaction speed test time did not change significantly across training days despite the presence of muscle soreness in many areas of the body.

\section{Practical application}

Digital pain monitoring can bring important information for coaches, medical staff and players.

Archiving and longitudinal digital pain monitoring can help in injury prevention and team management.

Analysis of data from digital pain monitoring software can help in recognizing symptoms of overload and to minimize injury risk.

One-aspect (only heart rate, only physiological blood factors, only motor skills, only psychological or perceived factors) monitoring does not ensure a complete insight into a players' psychophysical state. Multi-aspect monitoring is required for reliable findings. 


\section{References}

Aoki, H., O'Hata, N., Kohno, T., Morikawa, T., Seki, J. (2012). A 15-year prospective epidemiological account of acute traumatic injuries during official professional soccer league matches in Japan. The American Journal of Sports Medicine, 40 (5), 1006-1014. DOI: $10.1177 / 0363546512438695$.

Bahr, R. (2009). No injuries, but plenty of pain? On the methodology for recording overuse symptoms in sports. British Journal of Sports Medicine, 43 (13), 966-972. DOI: 10.1136/bjsm.2009.066936.

Bergier, J. (2004). Tendencje w grze bramkarzy w piłce nożnej w zawodach najwyższej rangi. Obserwacja i ocena działań zawodników w zespołowych grach sportowych. Międzynarodowe Towarzystwo Naukowe Gier Sportowych, 5, 71-76.

Błażkiewicz, A., Grygorowicz, M., Białostocki, A., Czaprowski, D. (2018). Characteristics of goalkeeping injuries: a retrospective, selfreported study in adolescent soccer players. The Journal of Sports Medicine and Physical Fitness, 58 (12), 1823-1830. DOI: 10.23736/S0022-4707.18.07849-0.

Boudreau, S.A., Badsberg, S., Christensen, S.W., Egsgaard, L.L. (2016). Digital Pain Drawings: Assessing Touch-Screen Technology and 3D Body Schemas. The Clinical Journal of Pain, 32 (2), 139-145. DOI: 10.1097/AJP.0000000000000230.

Carfagno, D.G., Hendrix, J.C. III (2014). Overtraining syndrome in the athlete: current clinical practice. Current Sports Medicine Reports, 13 (1), 45-51. DOI: 10.1249/JSR.0000000000000027.

Chamari, K., Haddad, M., Wong, D., Dellal, A., Chaouachi, A. (2012). Injury rates in professional soccer players during Ramadan. Journal of Sports Sciences, 30 Suppl 1, S93-S102. DOI: 10.1080/02640414.2012.696674.

Coutts, A.J., Rampinini, E., Marcora, S.M., Castagna, C., Impellizzeri, F.M. (2009). Heart rate and blood lactate correlates of perceived exertion during small-sided soccer games. Journal of Science and Medicine in Sport, 12 (1), 79-84. DOI: 10.1016/j. jsams.2007.08.005.

DeHaven, K.E., Lintner, D.M. (1986). Athletic injuries: comparison by age, sport, and gender. The American Journal of Sports Medicine, 14 (3), 218-224. DOI: 10.1177/036354658601400307.

Della Villa, F., Mandelbaum, B.R., Lemak, L.J. (2018). The Effect of Playing Position on Injury Risk in Male Soccer Players: Systematic Review of the Literature and Risk Considerations for Each Playing Position. American Journal of Orthopedics, 47 (10). DOI: 10.12788/ajo.2018.0092.

Deprez, D., Fransen, J., Boone, J., Lenoir, M., Philippaerts, R., Vaeyens, R. (2015). Characteristics of high-level youth soccer players: variation by playing position. Journal of Sports Sciences, 33 (3), 243-254. DOI: 10.1080/02640414.2014.934707.

Di Salvo, V., Benito, P.J., Calderón, F.J., Di Salvo, M., Pigozzi, F. (2008). Activity profile of elite goalkeepers during football match-play. The Journal of Sports Medicine and Physical Fitness, 48 (4), 443-446.

Egsgaard, L.L., Christensen, T.S., Petersen, I.M., Brønnum, D.S., Boudreau, S.A. (2016). Do Gender-Specific and High-Resolution Three Dimensional Body Charts Facilitate the Communication of Pain for Women? A Quantitative and Qualitative Study. JMIR Human Factors, 3 (2), e19. DOI: 10.2196/humanfactors.5693.

Fuller, C.W., Ekstrand, J., Junge, A., Andersen, T.E., Bahr, R., Dvorak, J., Hägglund, M., McCrory, P., Meeuwisse, W.H. (2006). Consensus statement on injury definitions and data collection procedures in studies of football (soccer) injuries. British Journal of Sports Medicine, 40 (3), 193-201. DOI: 10.1136/bjsm.2005.025270.

Goliński, D., Muracki, J., Wolański, P., Klich, S., Murawska-Ciałowicz, E. (2016). Small-sided soccer game (1v1) in goalkeepers' training. Central European Journal of Sport Science and Medicine, 16 (4) DOI: 10.18276/cej.2016.4-12.

Hägglund, M., Waldén, M., Ekstrand, J. (2003). Exposure and injury risk in Swedish elite football: a comparison between seasons 1982 and 2001. Scandinavian Journal of Medicine \& Science in Sports, 13 (6), 364-370. DOI: 10.1046/j.1600-0838.2003.00327.x.

Hägglund, M., Waldén, M., Bahr, R., Ekstrand, J. (2005). Methods for epidemiological study of injuries to professional football players: developing the UEFA model. British Journal of Sports Medicine, 39 (6), 340-346. DOI: 10.1136/bjsm.2005.018267.

Hootman, J.M., Dick, R., Agel, J. (2007). Epidemiology of collegiate injuries for 15 sports: summary and recommendations for injury prevention initiatives. Journal of Athletic Training, 42 (2), 311-319.

Hughes, J.D., Denton, K., Lloyd, R.S., Oliver, J.L., De Ste Croix, M. (2018). The Impact of Soccer Match Play on the Muscle Damage Response in Youth Female Athletes. International Journal of Sports Medicine, 39 (5), 343-348. DOI: 10.1055/s-0044-101147.

Kawczyński, A., Mroczek, D., Frąckiewicz, A., Chmura, P., Becella, L., Samani, A., Madeleine, P., Chmura, J. (2014). Effects of two recovery procedures after a football game on sensory and biochemical markers. The Journal of Sports Medicine and Physical Fitness, 54 (4), 394-402. 
Kawczyński, A., Samani, A., Fernández-de-Las-Peñas, C., Chmura, J., Madeleine, P. (2012). Sensory mapping of the upper trapezius muscle in relation to consecutive sessions of eccentric exercise. Journal of Strength and Conditioning Research, 26 (6), $1577-$ 1583. DOI: 10.1519/JSC.0b013e318234e589.

Knoop, M., Fernandez-Fernandez, J., Ferrauti, A. (2013). Evaluation of a specific reaction and action speed test for the soccer goalkeeper. Journal of Strength and Conditioning Research, 27 (8), 2141-2148. DOI: 10.1519/JSC.0b013e31827942fa.

Kristenson, K., Waldén, M., Ekstrand, J., Hägglund, M. (2013). Lower injury rates for newcomers to professional soccer: a prospective cohort study over 9 consecutive seasons. The American Journal of Sports Medicine, 41 (6), 1419-1425. DOI: $10.1177 / 0363546513485358$.

Lund, J.P., Donga, R., Widmer, C.G., Stohler, C.S. (1991). The pain-adaptation model: a discussion of the relationship between chronic musculoskeletal pain and motor activity. Canadian Journal of Physiology and Pharmacology, 69 (5), 683-694. DOI: 10.1139/ y91-102.

Maclntyre, D.L., Reid, W.D., McKenzie, D.C. (1995). Delayed muscle soreness. The inflammatory response to muscle injury and its clinical implications. Sports Medicine, 20 (1), 24-40. DOI: 10.2165/00007256-199520010-00003.

Muracki, J., Kumorek, M., Kisilewicz, A., Pożarowszczyk, B., Larsen, D.B., Kawczyński, A., Boudreau, S. (2019). Practical Use of the Navigate Pain Application for the Assessment of the Area, Location, and Frequency of the Pain Location in Young Soccer Goalkeepers. Journal of Human Kinetics, 69, 125-135. DOI: 10.2478/hukin-2019-0091.

Nie, H., Kawczynski, A., Madeleine, P., Arendt-Nielsen, L. (2005). Delayed onset muscle soreness in neck/shoulder muscles. European Journal of Pain, 9 (6), 653-660. DOI: 10.1016/j.ejpain.2004.12.009.

Padulo, J., Haddad, M., Ardigò, L.P., Chamari, K., Pizzolato, F. (2015). High frequency performance analysis of professional soccer goalkeepers: a pilot study. The Journal of Sports Medicine and Physical Fitness, 55 (6), 557-562.

Paquette, M.R., Peel, S.A., Schilling, B.K., Melcher, D.A., Bloomer, R.J. (2017). Soreness-related changes in three-dimensional running biomechanics following eccentric knee extensor exercise. European Journal of Sport Science, 17 (5), 546-554. DOI: 10.1080/17461391.2017.1290140.

Pawłowski, D., Trzaskoma, Ł. (2012). Szkolenie bramkarzy w piłce nożnej, wiek 12-16 lat. Poznań: Zysk i S-ka.

Rebelo, A., Brito, J., Maia, J., Coelho-e-Silva, M.J., Figueiredo, A.J., Bangsbo, J., Malina, R.M., Seabra, A. (2013). Anthropometric characteristics, physical fitness and technical performance of under-19 soccer players by competitive level and field position. International Journal of Sports Medicine, 34 (4), 312-317. DOI: 10.1055/s-0032-1323729.

Rebelo-Gonçalves, R., Figueiredo, A.J., Coelho-E-Silva, M.J., Tessitore, A. (2016). Assessment of Technical Skills in Young Soccer Goalkeepers: Reliability and Validity of Two Goalkeeper-Specific Tests. Journal of Sports Science \& Medicine, 15 (3), 516-523.

Shaballout, N., Neubert, T.A., Boudreau, S., Beissner, F. (2019). From Paper to Digital Applications of the Pain Drawing: Systematic Review of Methodological Milestones. JMIR mHealth and uHealth, 7 (9), e14569. DOI: 10.2196/14569.

Sieboth, R., Whitmore, T., Rodríguez, J., Lupescu, I., Oliseh, S., Miyamoto, T., ..., Steinegger, P. (2014). 2014 FIFA World Cup Brazil. Technical report and statistics, The FIFA Technical Study Group. Fédération Internationale de Football Association Editorial, Zurich.

Strand, E., Krosshaug, T., Andersen, T. (2011) Injury risk for goalkeepers in Norwegian male professional football. British Journal of Sports Medicine. 45.331. DOI: 10.1136/bjsm.2011.084038.59.

Tzatzakis, T., Papanikolaou, K., Draganidis, D., Tsimeas, P., Kritikos, S., Poulios, A., Laschou, V.C., Deli, C.K., Chatzinikolaou, A., Batrakoulis, A., Basdekis, G., Mohr, M., Krustrup, P., Jamurtas, A.Z., Fatouros, I.G. (2019). Recovery Kinetics After SpeedEndurance Training in Male Soccer Players. International Journal of Sports Physiology and Performance, 1-14. Advance online publication. DOI: 10.1123/ijspp.2018-0984.

Ziv, G., Lidor, R. (2011). Physical characteristics, physiological attributes, and on-field performances of soccer goalkeepers. International Journal of Sports Physiology and Performance, 6 (4), 509-524. DOI: 10.1123/ijspp.6.4.509.

Cite this anticle aS: Muracki, J. (2020). The Influence of Muscle Soreness on the Speed of Performing a Motor Reaction Speed Task in Football Goalkeepers During a Training Camp. Central European Journal of Sport Sciences and Medicine, 4 (32), 27-41. DOI: 10.18276/cej.2020.4-03. 